\title{
Correction to: Determination of Optimally Stable Posture for Force Actuator Based Articulated Suspension for Rough Terrain Mobility
}

\author{
Vijay Eathakota, Arun Kumar Singh, Srikanth Kolachalama, \\ and K. Madhava Krishna
}

\section{Correction to: \\ Chapter "Determination of Optimally Stable Posture for Force Actuator Based Articulated Suspension for Rough Terrain Mobility" in: P. Vadakkepat et al. (Eds.): \\ Trends in Intelligent Robotics, CCIS 103, https://doi.org/10.1007/978-3-642-15810-0_20}

The original version of this chapter was revised. The author name Srikanth Kolachalama was corrected. 